\title{
Digital health and primary care: Past, pandemic and
}

prospects

\section{Claudia Pagliari}

Global eHealth Group, Usher Institute, Edinburgh Global Health Academy \& Centre for Population Health Sciences, The University of Edinburgh Medical School, Edinburgh, UK

This article reflects on the breadth of digital developments seen in primary care over time, as well as the rapid and significant changes prompted by the COVID-19 crisis. Recent research and experience have shone further light on factors influencing the implementation and usefulness of these approaches, as well as unresolved challenges and unintended consequences. These are considered in relation to not only digital technology and infrastructure, but also wider aspects of health systems, the nature of primary care work and culture, patient characteristics and inequalities, and ethical issues around data privacy, inclusion, empowerment, empathy and trust. Implications for the future direction and sustainability of these approaches are discussed, taking account of novel paradigms, such as artificial intelligence, and the growing capture of primary care data for secondary uses. Decision makers are encouraged to think holistically about where value is most likely to be added, or risks being taken away, when judging which innovations to carry forward. It concludes that, while responding to this public health emergency has created something of a digital 'big bang' for primary care, an incremental, adaptive, patient-centered strategy, focused on augmenting rather than replacing existing services, is likely to prove most fruitful in the longer term.

\section{PRIMARY CARE AND THE SHOCK OF THE PANDEMIC}

What exactly constitutes 'primary care' is still somewhat contested, with definitions of the concept ranging from the philosophical and aspirational to the concrete and practical [1], while its professional scope varies across health systems [2]. For the purposes of this article, the term is used synonymously with family medicine or general practice, as described by the World Health Organization Europe [3].

The primary care setting is typically the first point of contact for patients seeking medical treatment, the setting in which most clinical and chronic disease management services are delivered, and a locus of referral to specialist care. It covers a wide variety of health needs, types of patients and processes, and often involves multidisciplinary teams. Patients and their families tend to have long-term relationships with their primary care doctor or practice, who typically holds their lifelong health record. Primary care may also integrate with other services, such as when delivering public health screening programs or managing patients with complex conditions in collaboration with clinical specialties. Making the best use of digital health requires careful consideration of these complexities, as well as technologies themselves.

Media headlines in the first wave of the coronavirus crisis were dominated by pressures on hospitals, but as the frontline of medicine in many countries, primary care services were also severely disrupted. Despite the initial shock, most were quick to adapt, due in large part, to the use of digital technologies, but this change has been easier and more rapid in some health systems than in others. 


\section{BUILDING ON THE STATUS QUO}

Many digital health innovations have been available in primary care settings for some time, although the extent to which they are used still varies widely, both between and within nations.

Electronic health records are a mainstay of primary care in many countries, integrating structured and unstructured patient data alongside coding systems, clinical decision support, e-prescribing, e-referral, and other features. Use of these systems is still patchy, however. While in some European countries, such as the UK and the Netherlands, primary care has been 'paperless' for years, elsewhere pockets of resistance can be seen [4]. Often this has less to do with money than professional cultures, silo-working, the absence of a strategy for primary care computing, or multiple public/private sector models that have hindered standardization. The coronavirus pandemic has shone further light on these systemic challenges and emphasized the value of strong information systems for safe, accurate, effective and coordinated care [5].

Hybrid digital methods, designed to support rather than replicate in-person care, are also being widely used. These include SMS appointment reminders (text messages), which can help to reduce 'no shows', and check-in kiosks which reduce administration time in primary care offices [6]. During COVID-19, mobile phone checkin may help to minimize the time spent in shared waiting rooms [7], increasing both efficiency and patient safety, given the risks of physical and airborne transmission [8].

Clinical queries sent via email or secure messaging systems can be useful for primary care patients seeking written health advice and clarification of medication or treatment plans, and may help to quickly differentiate the worried well from those requiring physical assessment. Wide international variation in the use of email consultation has been reported, however, and in Europe overall levels of usage remain low, with little indication that this has changed during the pandemic [9]. Concerns about workload, legal liability, confidentiality and patient safety have often been cited as barriers to implementation, although there is scant evidence of negative effects [10]. Policies aimed at ensuring that doctors can be reimbursed for email consultations have been introduced in some countries, but have had mixed success in changing practice [11] and new legal requirements, such as those in Denmark [12], may be needed.

Online patient portals and related apps are being used in primary care for appointment booking, ordering repeat medications and viewing test results, but access to and use of more detailed personal health records has lagged behind, even in countries where patients, in theory, have rights of access [13]. Opportunities for patients to view their medical notes and contribute personal health observations or device readings could improve empowerment and collaborative care for those undergoing treatment [14]. Health professionals have been somewhat reluctant to implement this functionality, however, largely due to concerns over added workload [15].

Although a number of countries, such as Germany [16], have brought patient portals onstream during the pandemic, most were already planned. Patient portals can also offer other potentially useful features, such as the ability to download relevant documentation when required for work, insurance or travel, which may have particular advantages in the context of social distancing. For example, England's NHS App now features a vaccine certification module, with print capabilities, which is likely to encourage many more citizens to adopt this portal technology in the coming months [17].

Experience of remote, virtual or tele-consulting has been growing over the last 20 years, and while fears over losing the human touch have dampened enthusiasm in primary care, trials have shown it to be acceptable and useful for some patients [18]. The pandemic has provided the catalyst needed to propel this into routine practice and there is huge optimism about its ongoing use. Recent experience at scale has yielded several lessons, however. On the one hand, adaptation to remote consulting has been easier than expected, helping to alter professional and patient perceptions. On the other hand, videoconferencing has proven less necessary or desirable than had previously been assumed, with telephone calls being equally or more acceptable in most cases [19]. Moreover, while video consulting has advantages for 'eyeballing' physical cues [20], it may also substantially increase general practitioner workload compared with telephone consulting [21]. As such, the rush of new video platform start-ups into the global telehealth market may be creating unnecessary demands and costs, which call for more guidance and standards [22]. Government-funded video consulting platforms are being rolled out in some countries but their normalization and sustainability in practice remains to be seen [23]. More 'frugal' forms of remote telemonitoring also hold potential, such as using SMS to enable 'automated hovering' over patients managing coronavirus symptoms at home, in a way that can trigger human intervention if the need arises [24].

Other forms of primary care telehealth have already moved into routine use, with clinical guidelines now recommending self-management using well-calibrated home monitoring devices, alongside usual care, for patients with long-term conditions [25]. During the pandemic the use of such devices is reported to have increased 
dramatically, although this has also raised concerns over maintaining their robustness, accuracy, privacy and safety [26].

\section{EMERGING INNOVATIONS}

Looking to the future, we can increasingly expect to see first-line queries triaged by chatbots, with or without Artificial Intelligence, which may direct patients to self-care advice or refer them to a clinician, depending on the answers to successive questions [27]. As the accuracy and safety of these tools are still in question, however, the risk threshold for triggering human intervention needs to be fairly low, thus introducing such technologies may potentially add, rather than reduce clinical time pressures at this stage [28].

Wearables create similar dilemmas. On the one hand, they provide more ambulatory data and can give more freedom to the patient. On the other hand, they can pose greater responsibility for clinicians to monitor this data, if used as part of a supported care plan. Continuous monitoring also has potential to trigger hospital admission through false positives or simply by surfacing symptom readings that would not have been apparent before, as has been seen in patients with COPD [29,30]. While certain wearables are already being deployed successfully in primary care, for example in ambulatory blood pressure monitoring, as the use of such devices becomes more common and diverse, so will be the volume, variety and complexity of the readings they generate. This is likely to become problematic for clinicians to manage and interpret, calling for the introduction of user-friendly and clinically accurate multi-parameter dashboards, as well as further standards to ensure safety and cost-effectiveness [31].

Wearables have nonetheless proven useful for enabling care at a distance during the pandemic, such as for monitoring vital signs in patients recuperating at home, where usual community-based follow up has been curtailed [32].

The integration of machine learning and Artificial Intelligence into clinical software, decision support tools and apps in primary care has potential to help optimize and personalize treatments. However, it will be essential for clinicians to recognize the risk of bias and harm when using these technologies, and ensure that they have been appropriately tested, regulated and approved. They also need to recognize that algorithms, even if technically robust, may be fed by data or evidence which is flawed, incomplete, unrepresentative or outdated. As such, despite the promise of such methods, the continued need for sound clinical judgment cannot be understated [33].

Introducing speech recognition technology into the consulting room has been proposed as one way of reducing administrative burden, by automating clinical documentation. While the use of voice assistants as 'digital scribes' has been trialled, technical, structural, ethical and legal difficulties mean these are still some way from routine use [34].

Other digital innovations likely to impact primary care practice include diagnostic 'laboratory-on-a-chip' devices, for analysing biosamples, which have potential to improve efficiency by quickly surfacing clinical insights previously only measurable in specialist facilities [35]. Similarly, with more sophisticated imaging capabilities being integrated into smartphones, we can anticipate greater use of pocket-sized visual diagnostics in the context of primary care and community medicine [36].

\section{WORK, ORGANIZATION AND VALUE}

The structure of primary care work has also evolved over time, with single-handed practitioners increasingly joining collaborative partnerships and even multi-specialty primary care centres, in places where the population is large enough to sustain them [37]. Such centres may be able to offer a much wider range of services, including mental health and minor surgery, using technology-supported triage to direct patients to the most appropriate and cost-effective service for their health issue. While the latter approach may not be feasible in many settings, in a future pandemic it might be possible to rapidly assemble and deliver this virtually, with the right digital platforms and agreements. Some countries have already launched ambitious plans for nationalscale digital triage, catalysed by COVID-19. This includes NHS England's 'digital first', strategy, which aims to ensure that all primary care is routed through an online triaging system, which directs patients to either online, telephone, or video consulting before a face to face consultation [38].

Despite the attractions of 'smarter' service allocation, health service planners must be careful to avoid technocentric over-optimism, which neglects the therapeutic value of clinical relationships and care continuity. Having a known family doctor who cannot only access the patient's digital record, but also has an informal knowledge of their health history, needs and circumstances, offers considerable advantages in primary care. For example, 
it may provide more context for symptom interpretation, empathy for understanding barriers to treatment compliance, and a trusted environment for sharing health concerns or debunking misinformation, as we have seen so much of during the coronavirus 'infodemic' [39]. While digital hand-off to any suitably qualified practitioner may be safe and acceptable for patients presenting with minor acute illness, for those with complex needs or the elderly, this is likely to be a false economy [40].

Wholesale conversion to online consulting in primary care is also ill-advised. Patients may have difficulties articulating their symptoms at a distance, and clinic-based follow up and testing will be needed to minimize the possibility of harm from undiagnosed disease, particularly in health systems where specialist medicine is accessed via primary care referrals. Likewise, failing to appropriately escalate patients from protocolized telephone advice to medical care may have serious clinical consequences and can damage trust in legitimate telehealth services, calling for high levels of vigilance and rigorous training for call handlers [41].

Experience of remote telemonitoring in primary care has also revealed the importance of initial training for patients and professionals, to gain the most value and avoid expensive or dangerous errors [42]. Managers should factor this into their cost-calculations, and not assume a plug-and-play scenario.

Pressures on clinicians to manage more patients without additional time, have been blamed for professional burnout, which has been magnified during the coronavirus crisis [43]. While some types of AI could help to alleviate administrative burdens or act as a cognitive prosthesis for clinicians making complex decisions at speed, reliance on 'black box' decision support could, paradoxically, exacerbate moral stress if clinicians are unable to judge the validity or safety of algorithmic recommendations [44]. As such, thinking carefully about how AI fits with or could disrupt clinical workflow and expertise, will be vital if these systems are to be safely introduced.

\section{THE ROLE OF HEALTH SYSTEMS}

It is not possible to consider the future of digital primary care without also considering the broader health systems in which this is taking place. Although universal health coverage is regarded as the gold standard, many countries still rely on a combination of government and self-funded primary care, whether out-of-pocket or via private insurance [45]. Digital health may create opportunities for patients in these settings to manage their health more affordably, by encouraging preventive lifestyle changes, facilitating disease self-management, and by lowering the direct and indirect costs of clinic visits, travel or unpaid time off work. More research is needed to verify these savings, however, with most such predictions coming from the industry itself [46].

Even in countries with free access to primary care, such as the UK, new businesses offering to deliver private video consulting services and rapid appointments are proliferating. While these offer speed and convenience for patients with the money to pay, they also increase existing health inequalities and risk eroding the statefunded primary care workforce. It may also tempt some governments to nudge patients towards paying twice for their care - once through their taxes and once from their taxed salaries, creating unfairness even for those with the most resources.

Primary care is a luxury that people in many countries can't easily obtain, either because there are too few doctors, or communities are too remote and widespread to sustain local health facilities. For this reason, the value proposition for remote or computer-driven primary care may be greater in resource-constrained regions. For example, using smartphone protocols to augment the skills of a community health worker may provide a 'virtual' nurse or doctor in human form [47], chatbots or simpler mobile phone question-answering tools may significantly improve preventive and self-care, and mobile telehealth services may connect people in communities to primary care doctors located elsewhere [48].

Meanwhile some branches of the digital tech industry are exploring opportunities to by-pass conventional primary care altogether. For example, China's Ping An Good Doctor has been rolling out unstaffed AI-assisted telemedical booths in shopping centres, which can undertake triage, preliminary diagnostics and even prescribing, while automatically referring the attendee for specialist care if merited [49]. While technologies like this may offer an affordable option for patients in highly unequal and underserved health systems, such impersonal approaches are likely to be resisted in Europe and other countries with strong primary care traditions.

As already noted, global health systems vary widely in their digital maturity, for historical reasons, such as the prioritization of technology and information infrastructures, policies and incentives favouring innovation, and workforce adaptability [5]. Likewise, countries' ability to respond to public health emergencies like COVID-19 is also bound up with the broader organization and funding of their health systems, particularly differences in the provision of universal health coverage. Deficiencies in the US response, for example, have been blamed 
on under-resourced, disconnected, unequal and unaffordable primary care [50]. As other experts have noted, weak primary health care systems don't suddenly become strong because you introduce digital health [51].

\section{DATA, CONTROL AND TRUST}

The need for health data is magnified during public health emergencies and, as the holder of most citizens' health records, primary care is one the richest sources of such data in many countries. During the COVID-19 pandemic, failures to adequately utilise primary care data to support a coordinated public health response have been sharply criticized [52]. Patient data from primary care have nevertheless been harnessed and linked with other sources of data, to inform national outbreak surveillance [53], understand service pressures [54], seed biomedical research [55], develop risk algorithms [56] and analyse inequalities to inform clinical and public health interventions $[57,58]$, amongst other uses.

While professional obligations and regulations have tightly controlled the release of primary care records for secondary uses in the past, a number of countries are now beginning to automate the extraction of coded patient data from primary care information systems, at scale, into centralized (or functionally centralized) digital platforms [59]. The linkage and analysis of this 'big data' has potential to inform improvements in health care efficiency, quality, treatments, disease prevention and patient outcomes, and has led to some valuable insights about COVID-19 [60]. However, it also creates significant privacy and security risks, which have not yet been fully put to the test and, if mishandled, may damage public trust [61]. This trust can be particularly fragile when commercial actors are involved, as has been seen in debates over the role of global technology giants in the pandemic response [62]. Meaningful public consultation, appropriate anonymization, opt-out mechanisms, strong security and effective regulatory oversight will all be needed to ensure that these uses of patient information are acceptable, safe, proportionate, fair and legal. This is relevant to primary care practice, not only because of the type of personal data it generates, but also because many patients believe their trusted family doctor has control over decisions about how their health information may be re-used, which is increasingly no longer the case, creating room for tension in the clinical relationship. It may also disempower primary care doctors who have previously had greater control over their patients' information, although this may be partially balanced through reciprocal data reports that can help to improve patient care [63]. Insensitive handling of such projects also risks significant legal push-back and reputational damage, as is currently being seen in the UK, fuelled in part by suspicions of data opportunism in the context of COVID-19 [64].

Aside from such major programs, which are often directed by governments, the data generated through the use of digital technologies in primary care is also being mediated by a plethora of businesses, such as providers of software, devices, apps and cloud hosting services, whose information governance processes can be hard to fathom [65]. As the use of digital tools in primary care grows, so will the need for clinicians and managers to ensure suppliers are adhering with relevant privacy and security requirements. Being able to rely on a trusted, standardized, verified and accountable digital health ecosystem will help to reduce this burden, but such collaborative enterprises also need effective governance, and not only by the industry itself [66].

These issues are being amplified as digital platform giants like Amazon, Apple and Google move into primary care. While most are currently prioritising telehealth and digital triage, their vast data ecosystems, coupled with advanced analytics capabilities, put them in a unique position to learn from and synthesise human decision-making, and potentially even empathy, raising new ethical dilemmas around patient trust and safety [67].

\section{UNDERSTANDING PATIENTS AND COMMUNITIES}

Just as with primary care professionals and organizations, the patients and communities they serve can vary widely in their readiness for digital change. Patient characteristics, circumstances and preferences can also influence the value that may be obtained from different digital health opportunities.

Those who are already familiar with video consulting may benefit more from this medium than others, for example, while email consulting may offer welcome time-saving for young professionals but leave the elderly disempowered and under-treated [68]. Similarly, while access to detailed health records may greatly benefit some patients, it may be confusing or alarming for others, could be misused by coercive actors, or may unintentionally betray the confidentiality of third parties, calling for careful conversations with patients at risk, and appropriate data redaction efforts [69].

Long-standing social inequalities in health status, health literacy and health empowerment are also manifested in the 'digital health divide', whereby those with the means to access and use these new opportunities 
can further enhance their health, whilst those without may fall further behind. As the frontline of medicine, primary care needs to pay special attention to digital inclusion [70]. In practical terms, cheap and accessible approaches, like telephone, SMS text messaging and print may be preferable to sophisticated smartphone apps for reaching low income communities or the elderly, and in many cases are just as effective. As digital gradually becomes the default mode for accessing services or obtaining support between consultations, novel approaches such as 'prescribing' digital devices and training, or deploying digitally-skilled patient navigators, will be needed to ensure fair access for those with the greatest need [71].

Anecdotal reports in the early days of home telemonitoring suggested that some doctors were reluctant to trust the data being brought to them by patients, preferring to rely on episodic in-clinic measures, despite richer information being available from continuous recording. With more standards in place and wearables now being directly issued in primary care, this barrier is likely to reduce, although trust in patient-generated data remains highly conditional [72]. Recent studies of telehealth suggest that while patients with serious long-term conditions may be greatly comforted by having their symptoms monitored at a distance, some doctors fear that this will encourage dependency, illustrating how value judgements can also influence decision making [73].

So called Health 2.0 has impacted primary care since the dawn of the Internet, with greater access to online health information enabling patients to have more informed discussions with their doctors and doctors to direct their patients to relevant resources. Professional concerns about the clinical time needed to correct misunderstandings about evidence or treatments have previously been expressed [74]. The dramatic rise of social media misinformation and disinformation during the pandemic suggests that new training and skills in infodemic management will be needed if primary care is to remain practically manageable and maintain mutual trust and respect in the therapeutic encounter [75].

Understanding people's personal circumstances and attitudes is not only vital for ensuring the appropriate use of alternative methods but can also be critical for their effective design. Previous waves of telehealth optimism have foundered on insufficient understanding of patient needs and primary care workflow, leading to poor design decisions, involving intrusive technologies or unrealistic expectations for clinician monitoring [76,77]. Accounts of patients left hanging around in simulated waiting rooms during the pandemic echo this failure and call for designing with and for users, not just digitizing existing services [78].

\section{MOVING FORWARD}

As we move beyond the pandemic, new norms around digitally-augmented and collaborative medicine are likely to develop, reflecting both generational and technological trends, but human primary care will remain a vital requirement for effective, fair and sustainable health systems [79].

Unresolved challenges around privacy, patient safety, equity, rights, empathy and trust, call for more attention to be paid to the unique ethical challenges of digital health in primary care and new guidelines, tailored to this specific context, are warranted.

When the public health emergency ends, digital first approaches and expedited data sharing agreements that were implemented out of necessity should be reviewed. Evidence on the effectiveness of digital health in primary care is still nascent [80] and while it makes sense to harness the momentum of the pandemic to modernize aspects of the service, serious thought should be given as to what other valuable aspects of primary care may be lost in the process.

Digital transformation in primary care has occurred in incremental steps, but remarkable progress has been achieved over time. Experiences gained during the pandemic have proven useful for driving adoption, altering mindsets and learning lessons, but given the complexities involved in this human-centred discipline, further progress is likely to be gained through an ongoing process of evolution and adaptation rather than revolution and disruption.

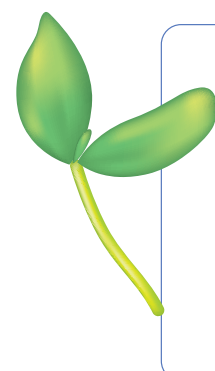

Acknowledgements: This paper builds on an interview for the policy magazine ICT\&Health. Thanks to Professor Lewis Ritchie for comments on the draft manuscript.

Funding: The author holds a UK Research and Innovation grant on The Role of Good Governance and the Rule of Law in Building Public Trust in Data-Driven Responses to Public Health Emergencies. Grant number: AH/V015214/1.

Authorship contributions: CP is the sole author.

Competing interests: The author completed the ICMJE COI form (available upon request from the corresponding author), and declares no conflict of interest. 
1 Factsheet WHO. Primary Health Care. 2021. Available: https://www.who.int/news-room/fact-sheets/detail/primary-health-care. Accessed: 15 June 2021.

2 Defining Primary Care. NCBI Bookshelf, citing Donaldson MS, Yordy KD, Lohr KN, and Vanselow NA. Eds. Institute of Medicine. Committee on the Future of Primary Care; Washington (DC): National Academies Press (US); 1996.

3 WHO Europe. Primary Health Care, Main Terminology. Available: https://www.euro.who.int/en/health-topics/Health-systems/ primary-health-care/main-terminology. Accessed: 15 June 2021.

4 European Commission. eHealth adoption in primary healthcare in the EU is on the rise. March 8th, 2021 Available: https://digitalstrategy.ec.europa.eu/en/library/ehealth-adoption-primary-healthcare-eu-rise. Accessed: 51 June 2021.

5 Liaw ST, Kuziemsky C, Schreiber R, Jonnagaddala J, Liyanage H, Chittalia A. et al. Primary Care Informatics Response to Covid-19 Pandemic: Adaptation, Progress, and Lessons from Four Countries with High ICT Development. Yearbook of Medical Informatics. 2021. Stuttgart: Georg Thieme Verlag KG.

6 Schwebel FJ, Larimer ME. Using text message reminders in health care services: A narrative literature review. Internet Interv. 2018;13:82-104. Medline:30206523 doi:10.1016/j.invent.2018.06.002

7 InTouch. New check-in app helps social distancing measures and infection prevention at Poole Hospital. Undated. Available: https:// www.intouchwithhealth.co.uk/patient-mobile-check-in-poole-hospital/. Accessed: 15 June 2021.

8 Greenhalgh T, Jimenez JJ, Prather PA, Tufekci Z, Fisman D, Schooley R. Ten scientific reasons in support of airborne transmission of SARS-CoV-2. Lancet. 2021;397:1603-5. Medline:33865497 doi:10.1016/S0140-6736(21)00869-2

9 Newhouse N, Lupiáñez-Villanueva F, Codagnone C, Atherton H. Patient Use of Email for Health Care Communication Purposes Across 14 European Countries: An Analysis of Users According to Demographic and Health-Related Factors. J Med Internet Res. 2015;17:e58. Medline:25798912 doi:10.2196/jmir.3700

10 Antonio MG, Petrovskaya O, Lau F. The State of Evidence in Patient Portals: Umbrella Review. J Med Internet Res. 2020;22:e23851. Medline:33174851 doi:10.2196/23851

11 Huygens MWJ, Swinkels ICS, Verheij RA, Friele RD, van Schayck OCP, de Witte LP. Understanding the use of email consultation in primary care using a retrospective observational study with data of Dutch electronic health records. BMJ Open. 2018;8:e019233. Medline:29358442 doi:10.1136/bmjopen-2017-019233

12 Grønning A, Assing Hvidt E, Nisbeth Brøgger MN, Fage-Butler A. How do patients and general practitioners in Denmark perceive the communicative advantages and disadvantages of access via email consultations? A media-theoretical qualitative study. BMJ Open. 2020;10:e039442. Medline:33109668 doi:10.1136/bmjopen-2020-039442

13 Essen A, Scandurra I, Gerrits R, Humphrey G, Johansen MA, Kierkegaard P, et al. Patient access to electronic health records: Differences across ten countries. Health Policy Technol. 2018;7:44-56. doi:10.1016/j.hlpt.2017.11.003

14 Esch T, Mejilla R, Anselmo M, Podtschaske B, Delbanco T, Walker J. Engaging patients through open notes: an evaluation using mixed methods. BMJ Open. 2016;6:e10034. Medline:26826154 doi:10.1136/bmjopen-2015-010034

15 Nøst TH, Faxvaag A, Steinsbekk A. Participants' views and experiences from setting up a shared patient portal for primary and specialist health services- a qualitative study. BMC Health Serv Res. 2021;21:171. Medline:33627122 doi:10.1186/s12913-02106188-8

16 Grote-Westrick M. New German digital project paves the way for online access to personal electronic health records. BMJ Opinion. Dec 18th, 2021. Available: https://blogs.bmj.com/bmj/2021/02/18/new-german-digital-project-paves-the-way-for-online-access-topersonal-electronic-health-records/. Accessed: 15 June 2021.

17 NHS Digital. Coronavirus (COVID-19) vaccination status for travelling abroad. June 10th, 2021 NHS Crown Copyright. Available: https://www.nhs.uk/conditions/coronavirus-covid-19/coronavirus-vaccination/vaccination-status-for-travelling-abroad/. Accessed: 15 June 2021.

18 Walker RC, Tong A, Howard K, Palmer SC. Patient expectations and experiences of remote monitoring for chronic diseases: Systematic review and thematic synthesis of qualitative studies. Int J Med Inform. 2019;124:78-85. Medline:30784430 doi:10.1016/j. ijmedinf.2019.01.013

19 Murphy M, Tong A, Howard K, Palmer SC. The implementation of remote consulting in UK primary care following the COVID-19 pandemic: a mixed-methods longitudinal study. Br J Gen Pract. 2021;71:e166-77. Medline:33558332 doi:10.3399/BJGP.2020.0948

20 Wherton J, Greenhalgh T. Evaluation of the Near Me video consulting service in Scotland during COVID-19, 2020. Scottish Government Social Research Series, March 2021. Available: www.gov.scot/socialresearch. Accessed: 15 June 2021.

21 Salisbury C, Murphy M, Duncan P. The Impact of Digital-First Consultations on Workload in General Practice: Modeling Study. J Med Internet Res. 2020;22:e18203. Medline:32543441 doi:10.2196/18203

22 Telemedicine Market 202. Top trends revolutionizing the regional industry demand through 2026 | North America, Europe \& APAC. Graphical Research Feb 2021. Available: https://www.globenewswire.com/news-release/2021/02/03/2168840/0/en/Telemedicine-Market-2021-Top-trends-revolutionizing-the-regional-industry-demand-through-2026-North-America-Europe-APACGraphical-Research.html. Accessed: 15 June 2021.

23 Alami H, Gagnon MP, Wootton R, Fortin JP, Zanaboni P. Exploring factors associated with the uneven utilization of telemedicine in Norway: a mixed methods study. BMC Med Inform Decis Mak. 2017;17:180. Medline:29282048 doi:10.1186/s12911-017-0576-4

24 Morgan AU, Balachandran M, Do D, Lam D, Parambath A, Chaiyachati KH, et al. Remote Monitoring of Patients with Covid-19: Design, implementation, and outcomes of the first 3,000 patients in COVID Watch. NEJM Catal Innov Care Deliv. 2020 Jul 21. Available: https://catalyst.nejm.org/doi/full/10.1056/CAT.20.0342. Accessed: 15 June 2021.

25 National Institute for Clinical Excellence. Chronic heart failure in adults: Diagnosis and management. Full Guideline, Sep 2018. UK National Guidelines Centre. Available: https://www.nice.org.uk/guidance/ng106/evidence/full-guideline-pdf-6538850029. Accessed: 15 June 2021.

26 Gerke S, Shachar C, Chai PR, Cohen G. Regulatory, safety, and privacy concerns of home monitoring technologies during COVID-19. Nat Med. 2020;26:1176-82. Medline:32770164 doi:10.1038/s41591-020-0994-1

27 Mesko B. Top 12 health chatbots. The Medical Futurist. 2020. Available: https://medicalfuturist.com/top-12-health-chatbots/ Accessed: 15 June 2021. 
28 Tielman ML, Neerincx MA, Pagliari C, Rizzo A, Brinkman W-P. Considering patient safety in autonomous e-mental health systems - detecting risk situations and referring patients back to human care. BMC Med Inform Decis Mak. 2019;19:47. Medline:30885190 doi:10.1186/s12911-019-0796-x

29 Hanley J, Pinnock H, Paterson M, McKinstry B. Implementing telemonitoring in primary care: learning from a large qualitative dataset gathered during a series of studies. BMC Fam Pract. 2018;19:118. Medline:30021535 doi:10.1186/s12875-018-0814-6

30 van der Burg J, Ahmad Aziz N, Kaptein MC, Breteler MJM, Joris HJ, van Vliet L, et al. Long-term effects of telemonitoring on healthcare usage in patients with heart failure or COPD. Clinical eHealth. 2020;3:40-8. doi:10.1016/j.ceh.2020.05.001

31 Piwek L, Ellis DA, Andrews S, Joinson A. The Rise of Consumer Health Wearables: Promises and Barriers. PLoS Med. 2016;13:e1001953. Medline:26836780 doi:10.1371/journal.pmed.1001953

32 Best J. Wearable technology: covid-19 and the rise of remote clinical monitoring. BMJ. 2021;372:n413. Medline:33602670 doi:10.1136/bmj.n413

33 Lin SY, Mahoney MR, Sinsky CA. Ten Ways Artificial Intelligence Will Transform Primary Care. J Gen Intern Med. 2019;34:162630. Medline:31090027 doi:10.1007/s11606-019-05035-1

34 Quiroz JC, Laranjo L, Kocaballi AB, Berkovsky S, Rezazadegan D, Coiera E. Challenges of developing a digital scribe to reduce clinical documentation burden. NPJ Digit Med. 2019;2:114. Medline:31799422 doi:10.1038/s41746-019-0190-1

35 Khunti K. Near-patient testing in primary care. Br J Gen Pract. 2010;60:157-8. Medline:20202359 doi:10.3399/bjgp10X483454

36 O'Sullivan JW, Grigg S, Crawford W, Turakhia MP, Perez M, Ingelsson E, et al. Accuracy of Smartphone Camera Applications for Detecting Atrial Fibrillation.A Systematic Review and Meta-analysis. JAMA Netw Open. 2020;3:e202064. Medline:32242908 doi:10.1001/jamanetworkopen.2020.2064

37 Baird B, Reeve H, Ross S, Honeyman M, Nosa-Ehima M, Sahib B, et al. Innovative models of general practice. 2018, London: The Kings Fund. Available: https://www.kingsfund.org.uk/sites/default/files/2018-06/Innovative_models_GP_Kings_Fund_June_2018. pdf. Accessed: 15 June 2021.

38 NHS England. Digital First Primary Care. NHS UK. Undated. Available: https://www.england.nhs.uk/gp/digital-first-primary-care/. Accessed: 1 June 2021.

39 The COVID-19 infodemic. Lancet Infect Dis. 2020;20:875. Medline:32687807 doi:10.1016/S1473-3099(20)30565-X

40 Baird B. Digital-first primary care: helpful disruptor or unnecessary disruption? The Kings Fund. 15th October 2019. Available: https:/www.kingsfund.org.uk/blog/2019/10/digital-first-primary-care Accessed: 15 June 2021.

41 Conn D. Nurses barred from NHS 111 Covid clinical division after 60\% of calls unsafe. The Guardian. Oct 1st, 2020. Available: https://www.theguardian.com/world/2020/oct/01/nurses-barred-from-nhs-111-covid-clinical-service-after-60-of-calls-unsafe. Accessed: 15 June 2021.

42 Hammersley V, Parker R, Paterson M, Hanley J, Pinnock H, Padfield P, et al. Telemonitoring at scale for hypertension in primary care: An implementation study. PLoS Med. 2020;17:e1003124. Medline:32555625 doi:10.1371/journal.pmed.1003124

43 Williams ES, Rathert C, Buttigieg SC. The Personal and Professional Consequences of Physician Burnout: A Systematic Review of the Literature. Med Care Res Rev. 2020;77:371-86. Medline:31216940 doi:10.1177/1077558719856787

44 Boers SN, Jongsma KR, Lucivero F, Aardoom J, Büchner FL, de Vries M, et al. SERIES: eHealth in primary care. Part 2: Exploring the ethical implications of its application in primary care practice. Eur J Gen Pract. 2020;26:26-32. Medline:31663394 doi:10.10 80/13814788.2019.1678958

45 Wikipedia. Universal health care. Undated. Available: https://en.wikipedia.org/wiki/Universal_health_care. Accessed: 15 June 2021.

46 Snoswell CL, Taylor ML, Comans TA, Smith AC, Gray KC, Caffery LJ. Determining if Telehealth Can Reduce Health System Costs: Scoping Review. J Med Internet Res. 2020;22:e17298. Medline:33074157 doi:10.2196/17298

47 Anstey Watkins JO, Goudge J, Gómez-Olivé FX, Griffiths F. Mobile phone use among patients and health workers to enhance primary healthcare: A qualitative study in rural South Africa. Soc Sci Med. 2018;198:139-47. Medline:29335160 doi:10.1016/j.socscimed.2018.01.011

48 Jack A. Rwanda venture tests digital health potential in developing world. Financial Times. Jan 18th, 2021. Available: https://www. ft.com/content/4fe33c92-cbd5-459a-8df6-20d0dlf57ec8. Accessed: 15 June 2021

49 Lovett L. Ping An Good Doctor showcases AI-powered, unstaffed clinics. Mobihealth News. Nov 29th 2018. Available: https://www. mobihealthnews.com/news/apac/ping-good-doctor-showcases-ai-powered-unstaffed-clinics. Accessed: 15 June 2021.

50 Gawande A. To fix our broken healthcare system, start with primary care. Fast Co. Jan 6th, 2021. Available: https://www.fastcompany.com/90590937/atul-gawande-interview-haven-healthcare. Accessed: 15 June 2021.

51 Digital Health and Covid 19. Bull World Health Organ. 2020;98:731-2. Medline:33177768 doi:10.2471/BLT.20.021120

52 Pettigrew LM, van Schalkwyk M, Rechel B, Garlik R. Where's the integration between public health and primary care in the response to covid-19? BMJ Opinion February 18, 2021. Available: https://blogs.bmj.com/bmj/2021/02/18/wheres-the-integrationbetween-public-health-and-primary-care-in-the-response-to-covid-19/ Accessed: 15 June 2021.

53 Chief Medical Officer of Scotland. Coronavirus (COVID-19): daily data for Scotland. Available: https://www.gov.scot/publications/ coronavirus-covid-19-daily-data-for-scotland Accessed: 21 June 2021.

54 Watt T, Kelly E, Fisher R. Patient-level data analysis of the impact of COVID-19 on primary care activity in England. The Health Foundation, May 4th, 2021. Available: https://www.health.org.uk/news-and-comment/charts-and-infographics/use-of-primarycare-during-the-covid-19-pandemic-may-2021. Accessed: 15 June 2021.

55 Wood A, Denholm R, Hollings S, Cooper J, Ip S, Walker V, et al. Linked electronic health records for research on a nationwide cohort of more than 54 million people in England: data resource. BMJ. 2021;373:n826. Medline:33827854 doi:10.1136/bmj.n826

56 Clift AK, Coupland CAC, Keogh RH, Diaz-Ordaz K, Williamson E, Harrison EM, et al. Living risk prediction algorithm (QCOVID) for risk of hospital admission and mortality from coronavirus 19 in adults: national derivation and validation cohort study. BMJ. 2020;371:m3731. Medline:33082154 doi:10.1136/bmj.m3731

57 Mathur R, Rentsch CT, Morton CE, Hulme WJ, Schultze A, MacKenna B, et al. Ethnic differences in SARS-CoV-2 infection and COVID-19-related hospitalisation, intensive care unit admission, and death in 17 million adults in England: an observational cohort study using the OpenSAFELY platform. Lancet. 2021;397:1711-24. Medline:33939953 doi:10.1016/S0140-6736(21)00634-6 
58 UK Government. Factors influencing COVID-19 vaccine uptake among minority ethnic groups. Government publishing service UK. Jan 15th, 2021. Available: https://www.gov.uk/government/publications/factors-influencing-covid-19-vaccine-uptake-amongminority-ethnic-groups-17-december-2020. Accessed: 15 June 2021.

59 NHS Digital. General Practice Data for Planning and Research (GPDPR). May 26th, 2021. Available: https://digital.nhs.uk/dataand-information/data-collections-and-data-sets/data-collections/general-practice-data-for-planning-and-research. Accessed: 15 June 2021.

60 Bhaskaran K, Bacon S, Evans SJW, Bates CJ, Rentsch C, MacKenna B, et al. Factors associated with deaths due to COVID-19 versus other causes: population-based cohort analysis of UK primary care data and linked national death registrations within the OpenSAFELY platform. Lancet Reg Health Eur. 2021;6:100109. Medline:33997835 doi:10.1016/j.lanepe.2021.100109

61 Temperton J. NHS care.data scheme closed after years of controversy. Wired July 6th, 2016. Available: https://www.wired.co.uk/ article/care-data-nhs-england-closed. Accessed: 15 June 2021.

62 Molloy C. Will Big Tech save the NHS - or eat it alive? Open Democracy. March 3rd, 2020. Available: https://www.opendemocracy.net/en/ournhs/will-big-tech-save-the-nhs-or-eat-it-alive/. Accessed: 15 June 2021.

63 Hamilton A. eHealth \& Health Data in Scotland Receives Boost with NHS SPIRE. DIGIT March 29th, 2017. Available: https://digit. fyi/e-health-health-data-scotland-receives-boost-nhs-spire/. Accessed: 15 June 2021.

64 O'Dowd A. New GP data extraction scheme raises concern. BMJ. 2021;373:n1389. Medline:34049862 doi:10.1136/bmj.n1389

65 Pagliari C. Commercial health apps: in the user's interest? BMJ. 2019;364:11280. Medline:30898789 doi:10.1136/bmj.11280

66 Stern AD, Matthies H, Hagen J, Brönneke JB, Debatin JF. Want to See the Future of Digital Health Tools? Look to Germany. Harvard Business Review, Dec 2nd, 2020. Available: https:/hbr.org/2020/12/want-to-see-the-future-of-digital-health-tools-look-togermany. Accessed: 15 June 2021.

67 Akhtar A. Here's where tech giants like Microsoft and Amazon stand in their race to revolutionize healthcare. Business Insider. Apr 13, 2021. Available: https://www.businessinsider.com/how-microsoft-google-apple-amazon-are-investing-in-healthcare2021-4?r=US\&IR=T. Accessed: 15 June 2021.

68 Donaghy E, Atherton H, Hammersley V, McNeilly H, Bikker A, Robbins L, et al. Acceptability, benefits, and challenges of video consulting: a qualitative study in primary care. Br J Gen Pract. 2019;69:e586-94. Medline:31160368 doi:10.3399/bjgp19X704141

69 Antonio MG, Petrovskaya O, Lau F. The State of Evidence in Patient Portals: Umbrella Review. J Med Internet Res. 2020;22:e23851. Medline:33174851 doi:10.2196/23851

70 Majeed A, Maile EJ, Coronini-Cronberg S. Covid-19 is magnifying the digital divide. BMJ Blogs. Sept 1st, 2020. Available: https:// blogs.bmj.com/bmj/2020/09/01/covid-19-is-magnifying-the-digital-divide/. Accessed: 15 June 2021.

71 Sieck CJ, Sheon A, Ancker JS, Castek J, Callahan B, Siefer A. Digital inclusion as a social determinant of health. NPJ Digit Med. 2021:4:52. Medline:33731887 doi:10.1038/s41746-021-00413-8

72 Ostherr K, Borodina S, Bracken RC, Lotterman C, Storer E, Williams B. Trust and privacy in the context of user-generated health data. Big Data Soc. 2017:4:1-11. doi:10.1177/2053951717704673

73 Hanley J, Pinnock H, Paterson M, McKinstry B. Implementing telemonitoring in primary care: learning from a large qualitative dataset gathered during a series of studies. BMC Fam Pract. 2018;19:118. Medline:30021535 doi:10.1186/s12875-018-0814-6

74 Gallagher P. GPs threaten to remove patients who visit 'Dr Google' first. iNews. Oct 13th, 2017. Available: https://inews.co.uk/news/ uk/doctors-gps-dr-google-patient-list-97165. Accessed: 15 June 2021.

75 Call for applicants for 2nd WHO training in infodemic management. World Health Organisation. 17 March 2021. Available: https://www.who.int/news-room/articles-detail/call-for-applicants-for-2nd-who-training-in-infodemic-management. Accessed: 15 June 2021

76 Ure J, Pinnock H, Hanley J, Ure J, Kidd G, Tarling A, et al. Piloting tele-monitoring in COPD: a mixed methods exploration of issues in design and implementation. Prim Care Respir J. 2012;21:57-64. Medline:21785816 doi:10.4104/pcrj.2011.00065

77 Davis MM, Freeman M, Kaye J, Vuckovic N, Buckley DI. A systematic review of clinician and staff views on the acceptability of incorporating remote monitoring technology into primary care. Telemed J E Health. 2014;20:428-38. Medline:24731239 doi:10.1089/ tmj.2013.0166

78 Gerhardt W. Help! I'm stuck in the virtual waiting room... again: Here's why digital investments alone won't improve the patient experience. Deloitte. April 13th 2021. Available: https://www2.deloitte.com/us/en/blog/health-care-blog/2021/help-im-stuck-inthe-virtual-waiting-room-again.html. Accessed: 15 June 2021

79 OECD. Strengthening the frontline: How primary health care helps health systems adapt during the COVID 19 pandemic. 10 th Feb, 2021. Available: https://www.oecd.org/coronavirus/policy-responses/strengthening-the-frontline-how-primary-health-carehelps-health-systems-adapt-during-the-covid-19-pandemic-9a5ae6dal. Accessed: 15 June 2021.

80 van der Kleij RMJJ, Kasteleyn MJ, Meijer E, Meijer E, Bonten TN, Houwink EJF, et al. SERIES: eHealth in primary care. Part 1: Concepts, conditions and challenges. Eur J Gen Pract. 2019;25:179-89. Medline:31597502 doi:10.1080/13814788.2019.1658190 